\title{
Transplante de pâncreas
}

\section{Pancreas transplantation}

\section{Eleazar Chaib', Roberto Ferreira Meirelles Junior², Vinicius Rocha Santos ${ }^{3}$, Telesforo Bacchella ${ }^{4}$, Luiz Augusto Carneiro D'Albuquerque ${ }^{5}$}

\begin{abstract}
Chaib E, Meirelles Jr. RF, Santos VR, Bacchella T, D'Albuquerque LAC. Transplante de pâncreas. Rev Med (São Paulo). 2009 jul.-set.;88(3) ed. especial:138-42.

RESUMO: Diabéticos insulino-dependentes são susceptíveis a altas taxas de complicações secundárias. O transplante de pâncreas teve início na Universidade de Minesota em 1966, com altas taxas de insucessos. Porém, recentemente, este procedimento tem obtido melhores resultados, conjuntamente com outros transplantes de órgãos. Os autores analisam, retrospectivamente, os fatores associados a melhora nos resultados do transplante de pâncreas, entre eles a seleção dos doadores, a técnica de retirada do pâncreas, a cirurgia do receptor com drenagem da secreção pancreática exócrina na bexiga ou no jejuno, o protocolo de imunossupressão, as falhas técnicas como tromboses vasculares, hemorragias, rejeição e infecção no Hospital das Clinicas da Universidade de São Paulo. As sobrevidas do enxerto e dos pacientes são analisadas no período de 1997 a 2006.
\end{abstract}

DESCRITORES: Transplante de pâncreas. Doadores de tecidos. Transplante de órgãos/ efeitos adversos. Análise de sobrevida.

1. Professor Livre-Docente, Disciplina de Transplante de Fígado, Pâncreas e LIM 37 do Departamento de Gastroenterologia da FMUSP. Former Honorary Registrar, Department of Surgery, Addenbrookes Hospital, University of Cambridge, England, UK, (1991-1993). Former Clinical Fellow, Department of Transplantation Surgery, John Radcliffe Hospital, University of Oxford, England, UK (2006-2009).

2. Assistente-Doutor, Disciplina de Transplante de Fígado, Pâncreas e LIM 37 do Departamento de Gastroenterologia da FMUSP. Former Clinical Fellow, University of Minesota, USA.

3. Assistente, Disciplina de Transplante de Fígado, Pâncreas e LIM 37 do Departamento de Gastroenterologia da FMUSP. Clinical fellow de cirurgia hepatobiliar do Hospital Beaujon (Universidade de Paris VII).

4. Professor Associado, Disciplina de Transplante de Fígado, Pâncreas e LIM 37 do Departamento de Gastroenterologia da FMUSP. Former Clinical Fellow University of Pittsburgh, USA (1989-1991).

5. Professor Titular, Disciplina de Transplante de Fígado, Pâncreas e LIM 37 do Departamento de Gastroenterologia da FMUSP.

Endereço para correspondência: Disciplina de Transplante de Fígado, Pâncreas e LIM 37 do Departamento de Gastroenterologia da Faculdade de Medicina da Universidade de São Paulo. Av. Dr Eneas de Carvalho Aguiar $25599^{\circ}$ andar, CEP 05403-010, São Paulo, Brasil. E-mail: eleazarchaib @ yahoo.co.uk 


\section{HISTÓRICO}

$\mathrm{K}$ elly e Lillehei ${ }^{1}$, da Universidade de Minesota, realizaram o primeiro transplante de pâncreas em humanos, com ligadura do ducto pancreático para controle da secreção exócrina do pâncreas e muitas variantes técnicas foram descritas nas duas décadas seguintes. Gliedman et al. (1973) descreveram a técnica de drenagem urinária, para controle da secreção exócrina do pâncreas, que consistia na anastomose do ducto pancreático no ureter do receptor. Nove anos mais tarde, Cook e Sollinger, da Universidade de Wisconsin, descreveram a técnica de drenagem da secreção exócrina do pâncreas diretamente na bexiga.

\section{PRINCÍPIOS E JUSTIFICATIVAS}

Numerosos estudos sugerem que somente o controle estrito da glicemia previne efetivamente a progressão da retinopatia, nefropatia, polineuropatia e vasculopatia diabética. $O$ objetivo do transplante de pâncreas é melhorar a qualidade de vida dos pacientes diabéticos tipo 1 , retardando ou mesmo impedindo a progressão das complicações do diabetes mellitus, estabelecendo um estado de normoglicemia insulino-independente. O transplante de pâncreas é a alternativa mais segura para normalização os níveis de hemoglobina glicosilada do sangue do paciente diabético.

\section{MODALIDADES E INDICAÇÕES}

São três as categorias possíveis de transplante de pâncreas:

1. Transplante de Pâncreas Isolado - indicado para pacientes diabéticos chamados hiperlábeis, que se apresentam em coma por hiper ou hipoglicemia;

2.Transplante de Pâncreas e Rim Simultâneo indicado para pacientes diabéticos e nefropatas em diálise, com insuficiência renal crônica

3. Transplante de Pâncreas após Transplante de Rim - indicado para pacientes diabéticos que têm piora do enxerto renal por agravamento do diabetes.

\section{CRITÉRIOS DE SELEÇÃo PARA RECEPTORES}

1.Pacientes com idade entre 18 a 55 anos;

2. Pacientes diabéticos tipo I;

3.Pacientes não podem apresentar doença coronariana, obstrução das artérias ilíacas, doenças malignas e infecções.

\section{CRITÉRIOS DE EXCLUSÃO PARA RECEPTORES}

1. Incompatibilidade grupo sanguíneo $A B O$ entre o doador e o receptor;

2. Presença de "Crossmatch" - anticorpo do doador contra receptor.

3. Obesidade $\left(\mathrm{IMC}>30 \mathrm{Kg} / \mathrm{m}^{2}\right)$.

\section{CRITÉRIOS DE PRIORIZAÇÃO DE RECEPTORES}

1. Antígenos de histocompatibilidade semelhantes aos do doador;

2. Sorologia citomegalovírus (CMV) compatível com a do doador (doador e receptor com sorologia positiva ou doador e receptor com sorologia negativa);

3. Tempo em lista espera.

\section{CRITÉRIOS DE SELEÇÃO PARA DOADORES}

1. Morte encefálica (sem fluxo sanguíneo cerebral);

2. Idade de 02 a 50 anos;

3. Peso corpóreo > $30 \mathrm{~kg}$;

4. Sorologia para hepatites virais negativa;

5. Glicemia, Amilase e Lipase normais.

\section{PRÉ-OPERATÓRIO}

O potencial receptor ao transplante de pâncreas é submetido à anamnese e ao exame físico completo com particular atenção as manifestações do diabetes mellitus. Como rotina, são feitos Raio X de tórax, eletrocardiograma com prova de esforço (mapeamento cardíaco com tecnésio radiotavo) para avaliação de possível isquemia miocárdica e angiografia abdominal e de membros inferiores para avaliação das artérias ilíacas e periféricas dos membros inferiores. A avaliação metabólica inclui dosagens da glicemia, peptídeo C- reativo e insulina. O pré-operatório inclui também sorologias para CMV, e HIV. A presença e o grau de retinopatia é avaliado pelo oftalmologista, enquanto a neuropatia diabética pode ser diagnosticada por exames de eletromiografia. Ultrasonografia abdominal superior deve ser realizada para exclusão de colelitíase e, finalmente, uma abordagem psicossocial é necessária para avaliar se o paciente possui entendimento da natureza do procedimento e suas complicações.

\section{CIRURGIA DO DOADOR}

A retirada do enxerto pancreático geralmente é parte da retirada de múltiplos órgãos intra-abdominais. Como o pâncreas e o fígado compartilham de um mesmo suprimento arterial, e variações anatômicas 
Chaib E, Meirelles Jr. RF, Santos VR, Bacchella T, D’Albuquerque LAC. Transplante de pâncreas.

são comuns, uma cuidadosa dissecção e um bom entendimento entre as equipes de retirada do pâncreas e fígado são fundamentais para o sucesso da operação.

A técnica cirúrgica se resume a:

1. secção completa do omento maior;

2. exposição da face anterior do pâncreas por rebatimento do ângulo hepático do cólon, do cólon transverso e do ângulo esplênico do cólon;

3. exposição completa da cabeça do pâncreas através da manobra de Kocher;

4. secção da primeira porção do duodeno e do jejuno, utilizando-se grampeadores lineares;

5. secção dos vasos gástricos curtos e de possíveis aderências do pâncreas e rebatimento cranial do estômago;

6. liberação do corpo e da cauda do pâncreas, juntamente com o baço. Nessa manobra, o tecido pancreático não deve ser tocado pelo cirurgião, todo o enxerto pancreático é manipulado através do baço;

7. identificação, ligamento e secção dos ramos da artéria e veia mesentéricas na raiz do mesentério, junto ao tecido pancreático;

8. secção da artéria mesentérica junto à aorta, liberando totalmente o enxerto pancreático;

9. retirada dos vasos ilíacos do doador, completando a retirada do enxerto;

10. imersão dos enxertos pancreático e vasculares em 1 litro de solução de Belzer.

$\mathrm{Na}$ cirurgia de mesa (back table) o enxerto pancreatoduodenal é preparado conforme descrito abaixo:

1. Remoção do baço;

2. Encurtamento do segmento duodenal (cerca de $10 \mathrm{~cm}$ );

3. Sutura e invaginação das bordas duodenais;

4. Nova ligadura da raiz do mesentério, colédoco e artéria gastroduodenal e veia mesentérica inferior;

5. Mobilização da veia porta;

6. Realização de enxerto vascular em Y (anastomose das artérias ilíacas do doador com os pedículos vasculares das artérias mesentérica superior e esplênica do enxerto pancreático) (Figura 1).

\section{CIRURGIA DO RECEPTOR}

A via de acesso normalmente usada é a laparotomia mediana. O implante do pâncreas é preferencialmente realizado na fossa ilíaca direita do receptor, uma vez que os vasos ilíacos direitos são mais acessíveis. O implante pancreático pode ser feito de forma que a produção endócrina do órgão seja drenada pelo complexo venoso sistêmico ou portal.

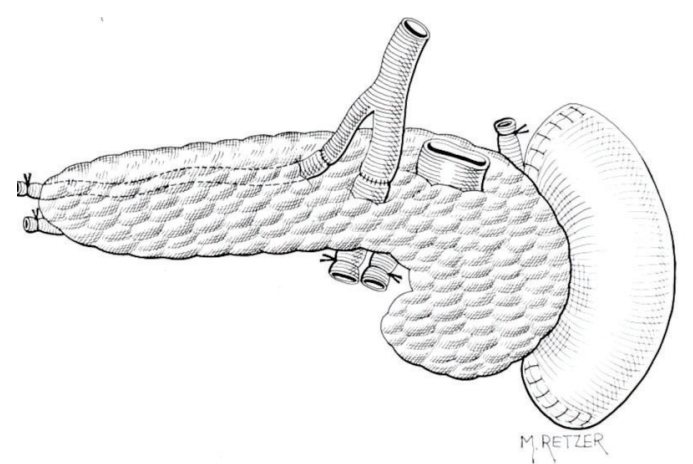

FIGURA 1. Cirurgia do doador (back-table): enxerto vascular em Y (artéria ilíaca externa do doador anastomosada com a artéria mesentérica superior e a artéria ilíaca interna com a artéria esplênica)

As principais etapas do implante do enxerto pancreático são:

1. Incisão mediana iniciada de 2 a $5 \mathrm{~cm}$ acima da cicatriz umbilical e estendidas até o púbis;

2. Exposição da bexiga (caso seja utilizada a derivação vesical de drenagem do conteúdo exócrino do pâncreas);

3. Mobilização, cranialmente, do ceco e do íleo terminal;

4. Exposição e mobilização dos vasos ilíacos (técnica semelhante à do transplante renal).

5. Anastomose término-lateral da veia porta do enxerto e a veia ilíaca comum do receptor (drenagem venosa sistêmica da secreção pancreática endócrina);

6. Anastomose término-lateral da artéria ilíaca comum do enxerto vascular em Y com a artéria ilíaca comum do receptor;

7. Revascularização do enxerto (hemostasia);

8. Drenagem da secreção exócrina pancreática do enxerto, que pode ser feita de suas maneiras: 8.1 drenagem vesical (anastomose láterolateral duodeno- vesical) (Figura 2); 8.2 drenagem entérica (anastomose látero-lateral duodeno-jejunal ou em Y de Roux) (Figura 3);

9. Revisão da hemostasia e lavagem da cavidade;

10. Fechamento da cavidade abdominal.

\section{IMUNOSSUPRESSÃO}

Atualmente, os esquemas de imunossupressão mais freqüentemente utilizados incluem 
medicamentos indutores como soros anti-linfocitários (anticorpos anti-células T monoclonais (OKT3), por exemplo), soros policlonais (ATG) ou medicamentos com anticorpos monoclonais anti-receptores de IL-2 (Basiliximab e Daclizumab). A manutenção da imunossupressão baseia-se na utilização de inibidor de calcineurina (Tacrolimus) associado a um anti-metabólito (micofenolato mofetil) e corticóide (prednisona).

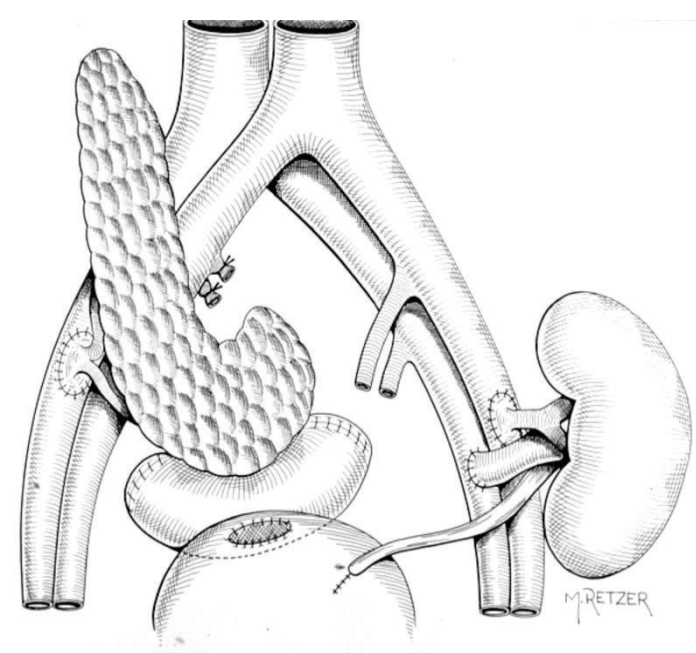

FIGURA 2. Cirurgia do receptor: drenagem da secreção exócrina pancreática do enxerto na bexiga (anastomose látero-lateral duodeno-vesical). Transplante duplo de pâncreas e rim

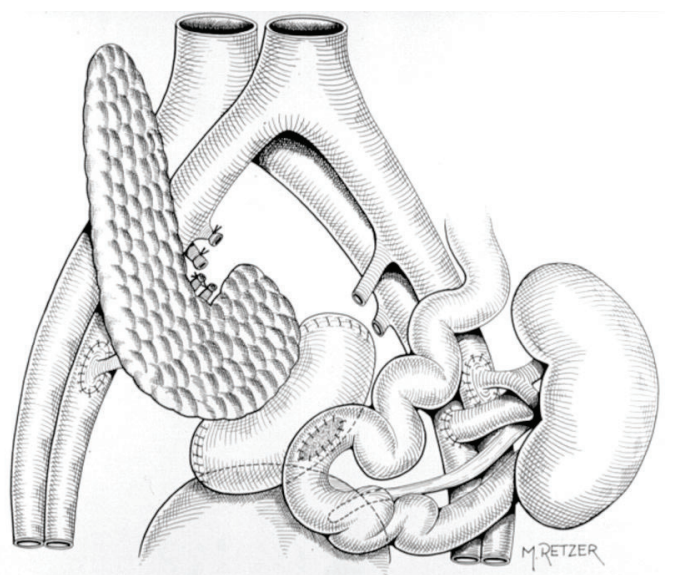

FIGURA 3. Cirurgia do receptor: drenagem da secreção exócrina pancreática do enxerto no jejuno (anastomose látero-lateral duodeno-jejunal). Transplante duplo de pâncreas e rim

\section{SOBREVIDA}

A sobrevida de 1 ano dos pacientes e dos enxertos pancreáticos de doadores cadáver realizados nos Estados Unidos, no período de 2002 a 2003, foi, respectivamente, de $95 \%$ e $85 \%$ para o transplante combinado de pâncreas e rim, $95 \%$ e $78 \%$ para o transplante de pâncreas após transplante de rim e de 98\% e $76 \%$ para o transplante de pâncreas isolado. Para os doentes submetidos a transplante combinado de pâncreas e rim com doador cadáver nos outros países, nesse mesmo período, a sobrevida de 1 ano foi de $94 \%$ e do enxerto de $87 \%{ }^{2}$.

Em nosso serviço no Hospital das Clínicas da Faculdade de Medicina da Universidade de são Paulo (HC/FMUSP) a curva de sobrevida do enxerto e do paciente pode ser vista no Gráfico 1.
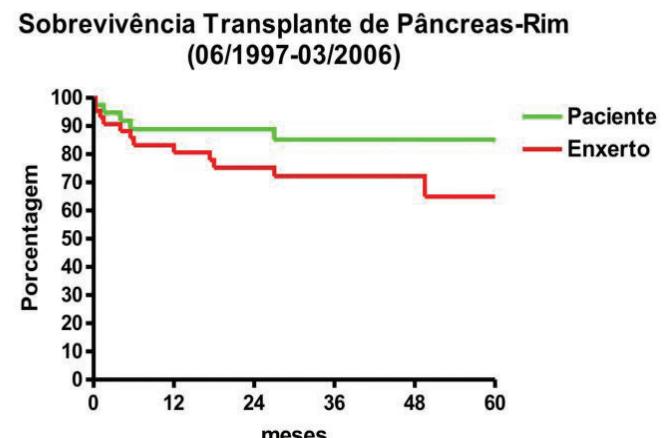

Sobrevivência em 12 meses Paciente $88,89 \%$

Sobrevivência em 60 meses Enxerto 83,20\%

Paciente 85,19\%

Enxerto 64,99\%

GRÁFICO 1. Sobrevivência do transplante de pâncreas-rim (pacientes e do enxerto) no Instituto Central do Hospital das Clínicas da FMUSP no período de 06/1997 à 03/2006

\section{COMPLICAÇÕES}

De maneira geral, a principal complicação relacionada à perda de enxerto pancreático é falha técnica da cirurgia, seguida de rejeição aguda ou crônica. Entende-se por falha técnica a perda do enxerto nos primeiros 3 meses de transplante devido a trombose vascular $(50 \%)$, pancreatite $(20 \%)$, infecção (18\%), fístulas (6,5\%) e hemorragia (2,4\%). Outras complicações são infecção e deiscência de parede abdominal ${ }^{3}$.

\section{NEOPLASIAS}

A doença linfoproliferativa é uma complicação rara e mais grave no transplante de pâncreas quando comparado a outros tipos de transplante. A sua incidência varia de 1 a 2,5\% e está, possivelmente, relacionada ao regime de imunossupressão e à presença de $\mathrm{CMV}^{4}$. 
Chaib E, Meirelles Jr. RF, Santos VR, Bacchella T, D’Albuquerque LAC. Transplante de pâncreas.

\section{COMPLICAÇÕES TARDIAS}

Tardiamente, as principais complicações estão relacionadas com quadro de rejeição crônica e complicações infecciosas, sendo causas importantes de mortalidade o infarto do miocárdio e morte súbita.

Chaib E, Meirelles Jr. RF, Santos VR, Bacchella T, D'Albuquerque LAC. Pancreas transplantation. Rev Med (São Paulo). 2009 jul.-set.;88(3) ed. especial:138-42.

\begin{abstract}
Insulin-dependent diabetes mellitus is associated with a high incidence of management problems and secondary complications. Clinical pancreas transplantation began at the University of Minnesota in 1966, initially with a high failure rate, but the outcome improved in parallel with other organ transplants. The authors retrospectively analyzed the factors associated with the increase success rate of pancreas transplants, among them donor selection, technical aspects of the retrieval of the pancreas, recipient operation with bladder drainage and Roux-en-Y for drainage of the exocrine pancreatic secretion, immunosupression protocol, technical failures such as vascular thrombosis, hemorrhages, rejection and infection at Hospital das Clinicas from University of Sao Paulo School of Medicine. Graft and patient survival rate is also described from 1997 to 2006.
\end{abstract}

KEY WORDS: Pancreas transplantation. Tissue donors. Organ transplantation/adverse effects. Survival analysis.

\title{
REFERÊNCIAS
}

1. Kelly WD, Lillehei RC, Merkel FK, Idezuki Y, Goetz FC: Allotransplantation of the pancreas and duodenum along with the kidney in diabetic nephropathy. Surgery. 1967;61:827-37.

2. Tyden G, Bolinder J, Solders G, Brattstrom C, Tibell A, Groth CG: Improved survival in patients with insulin-dependent diabetes mellitus and endstage diabetic nephropathy 10 years after combined pancreas and kidney transplantation. Transplantation. 1999;67:645-8.
3. Humar A, Ramcharan T, Kandaswamy R, Gruessner RW, Gruessner AC, Sutherland DE: Technical failures after pancreas transplants: why grafts fail and the risk factors - a multivariate analysis. Transplantation. 2004;78:1188-92.

4. Paraskevas S, Coad JE, Gruessner A, Kandaswamy R, Humar A, Sutherland DE, Gruessner RW. Posttransplant lymphoproliferative disorder in pancreas transplantation: a single-center experience. Transplantation. 2005;80:613-22. 